\title{
Exploring Geometry Teaching Model: Polygon Pieces and Dictionary Tools for the Model
}

\author{
Shakespear Maliketi Chiphambo ${ }^{1 *}$, Nosisi Nellie Feza ${ }^{1}$ \\ 1 Walter Sisulu University, SOUTH AFRICA
}

Received 11 March 2020 - Accepted 28 April 2020

\begin{abstract}
Research reveals that many mathematics teachers find it difficult to stimulate learners' interest in learning geometry. One major reason suggested is that geometric concepts are not well conceptualised and comprehended by both learners and teachers. The study explored learners' views on how polygon pieces and dictionary mediate learning of geometry. Nine Grade 8 learners were purposely selected from the cohort of 56 learners based on the diagnostic test results. By employing a qualitative approach through exploration data were gathered from semi- structured interviews and document analysis was implemented and reported in themes. The study found that polygon pieces with mathematics dictionary enhance learners' learning of geometry through geometric inquiry. Polygon pieces assisted learners with geometric conceptualisation through cutting, constructing and measuring of angles and line segments. The dictionary enhanced learners' geometric vocabulary by transferring informal vocabulary. We recommend mathematics teachers to integrate polygon pieces assisted by mathematics dictionary in the teaching and learning of mathematics.
\end{abstract}

Keywords: conceptual understanding, dictionary, polygon pieces, properties of triangles, unpack meaning

\section{INTRODUCTION}

Geometry is the branch of mathematics that deals with shapes and lines. Conceptual understanding of geometry is very important since the world we live is geometric naturally (Clements \& Battista, 1992). Geometry is an important part of the South African mathematics curriculum (Alex \& Mammen, 2016). Despite its importance many learners find it difficult to understand. The study done by Van Hiele (1999) reveals that school geometry is presented based on certain principles assuming that learners think at a formal logical level, yet most of the learners lack the basic conceptual understanding about geometry (Steele, 2013). According to the call in Trends in Mathematics Science Study (2015) most schools need interventions to improve learners' performance in mathematics (Reddy, Visser, Winnaar, Arends, Juan, Prinsloo, \& Isdale (2016). It is argued that designed interventions should integrate visual and verbal representations to enhance geometrical understanding (Alex \& Mammen, 2018).
Researchers argue that there are many challenges which learners encounter in their learning of the language of mathematics, to communicate mathematically demands a strong vocabulary knowledge base; flexibility; fluency and proficiency with numbers, symbols, words, diagrams; and comprehension skills (Riccomini, Smith, Hughes, \& Fries, 2015).

However, to enhance learners' geometric vocabulary and terminology, we present the integration of mathematics dictionary as tool of the model of teaching geometry. The integration of polygon pieces into the model also help on improving learners' conceptual understanding of geometry. The use of polygon pieces assisted by mathematics dictionary is to curb abstract teaching which leads to most learners failing to attach meaning to the geometric concepts.

Geometry being the compulsory subject in most of the science career fields, for example in architectural design; engineering and different areas of construction sector, researchers have noted that geometrical skills acquired at primary and high school levels are also of

(c) 2020 by the authors; licensee Modestum. This article is an open access article distributed under the terms and conditions of the Creative Commons Attribution License (http://creativecommons.org/licenses/by/4.0/). 


\section{Contribution to the literature}

- The study employs the integration of polygon pieces and dictionary as tools for newly developed geometry teaching model.

- Polygon pieces assisted learners with geometric conceptualisation through cutting, constructing and measuring of angles and line segments.

- The integration of dictionary in the lesson enhanced learners' geometric mathematical vocabulary and terminology by transferring informal vocabulary.

worthwhile (Alex \& Mammen, 2014; Van den Heuvel Panhuizen, Elia, \& Robitzsch, 2015). Research shows that problems encountered by learners in learning geometry are a result of how the subject is taught at all levels from primary to high school (Fujita \& Keith, 2003).

The existence of real-life fields of study that require geometry have made the authorities of education systems to consider geometry with the highest priority in school curricula right from primary level (Clements \& Sarama, 2011). Hence, Current research outputs show constant consideration in mathematics education in general and geometry education specifically (Alex \& Mammen, 2014; Moss, Hawes, Naqvi, \& Caswell, 2015).

It is evident that traditional teaching practices deny learners creativity and cripple learners' problem- solving skills. Mathematics teachers should understand that geometric conceptual understanding does not come suddenly; it requires an instructional process that matches figural and conceptual components using specific intervention strategies and well- integrated teaching and learning resources, in this case the integration of polygon pieces and mathematics dictionary (Bussi \& Frank, 2015; Luria, 1976). Most studies focus on the achievement results when physical manipulatives were used in the teaching and learning of mathematics. However, they do not focus on the integration of polygon pieces assisted by mathematics dictionary in the teaching and learning of geometry. Therefore, the paper adds a new dimension to the research on the use of polygon pieces assisted by mathematics dictionary for instruction.

Numerous research outcomes on the use of physical manipulatives in teaching of geometry reveal that they should be considered a priority (Correa, Perry, Sims, Miller, \& Fang, 2008; Puchner, Taylor, O'Donnell, \& Fick, 2008), of which it is the emphasis in this study. Even though there are inconsistent research findings on the advantages of instruction of mathematics using manipulatives, some research argue that they promote learning others say they hinder it (Laski, Jor'dan, Daoust, \& Murray, 2015). This implies that the use of physical manipulatives depends on how they are integrated into teaching and learning. For this reason, we present how the polygon pieces were assisted by mathematics dictionary to promote learning of geometry. There is an understanding that during the instructional process physical manipulatives give more clarity on concept being taught, but to define and explain the concept or to give the correct terminology which is of importance becomes difficulty to some learners. For this reason, this study integrates the dictionary into the model to enhance learners' ability to define and explain the concepts or terms in details for their own conceptual understanding.

According to Van Hiele (1999), vocabulary plays an important role in developing geometrical understanding hence we recommend the integration of polygon pieces and dictionary in the teaching and learning of geometry. This paper aims to respond to the call by exploring geometry teaching and learning model that integrates polygon pieces assisted by mathematics dictionary to help in enhancing learners' conceptual understanding of geometry.

The study focussed on the following question: How will the use of polygons pieces assisted by mathematics dictionary in teaching and learning of geometry influence learners' conceptual understanding of geometry concepts, specifically properties of triangles?

\section{THEORETICAL FRAMEWORK}

The van Hiele model of geometric thinking for learners' learning of geometry was used to frame the study to account for the exploration of the model that used polygon pieces assisted with mathematics dictionary. The model has five sequential and discrete levels as follows: visualization (recognising and naming the figures as they appear in different orientations), analysis (described the attributes of shapes using the point of reference), abstraction (classifying and generalising shapes by attribute through exploration and construction), formal deduction (proofs of shapes are developed using the inclusion shapes' properties, geometric vocabulary) and rigor (working with different geometrical systems, different proofs are given without using tangible items) (Alex, 2012). The levels are hierarchical and each has characterised by its own special language (van Hiele, 1999). The first four levels (visualisation, analysis, abstraction and formal deduction) are of focus for discussion in this article.

\section{RESEARCH DESIGN}

This paper employs qualitative design to present insight to the conceptual development of geometry ideas through semi-structured interviews that were later 
analysed and reported using a thematic report. A diagnostic was administered to the learners with the aim of identifying learners' challenges that were addressed by the intervention.

Based on the need arose in the diagnostic test, in phase two, the intervention programme was designed and administered to address not only the alternative conceptions learners demonstrated in the diagnostic test but also to teach the concepts of the properties of triangles in an informal activity-based way so that learners would be able to identify, classify and name triangles based on their properties. In the intervention programme, polygon pieces assisted by mathematics dictionary were used to engage learners in developing conceptual understanding of the properties of triangles.

Document review of learners' diagnostic and posttests scripts was also employed to help in identifying learners' misconceptions in areas that needed intervention to improve their understanding of geometric concepts. According to Bowen (2009) document review is a procedure of systematically reviewing or evaluating documents to obtain the data that have to be examined and interpreted to draw meaning, gain understanding and develop realistic knowledge (Corbin \& Strauss, 2008). Document review has been employed to seek convergence and corroboration of data from the learners' understanding of geometry and also to determine the influence of polygon pieces assisted with dictionary on learners' learning of geometry.

In order to make sense of the data from the two instruments, namely: semi-structured interviews and participants' diagnostics and post-tests scripts, comparative method (Glaser \& Strauss, 1967) guided the data analysis. The reviewed documents yielded data in a form of excerpts and quotations which were later organised into themes. The comparative method helped to identify patterns and discovering codes and theoretical properties in the data. Codes and concepts that belong together were identified in a constant back and forth exercise. We scrutinised data with data and with codes to identify similarities, differences, and general patterns (Bowen, 2008). The identified codes were later clustered together based on their similarities and differences which resulted in the themes that form the basis of the discussion.

\section{Validity}

Wiersma (1991) argues that validity involves two concepts concurrently, the accurate interpretation of the results (internal validity) and the extent to which the results can be generalised (external validity).

\section{Internal validity}

Researchers argue that every study has threats to internal validity, namely: history and maturation, selection bias, mortality, implementation, the attitudes of the subjects, data collector bias and data collector characteristics (Le Compte \& Goetz, 1982).

History refers to occurrences that may have an effect on the overall research study setup (Fraenkel \& Wallen, (2006). To avoid or minimise such occurrences all the participants were interviewed within the same day.

Maturation refers to the progressive development of individuals (Fraenkel \& Wallen, 2006). To reduce the effects of maturation the case study design which provides the opportunity of studying a particular phenomenon within a restricted time frame was employed (Bells, 1993).

Selection bias is the situation where the participants in the research are different from each other in terms of age, gender, ability, etc. (Fraenkel \& Wallen, 2006). The diagnostic test results were used to deal with selection bias for purposeful sampling, regardless of gender (Marshall, 1996).

According to Fraenkel and Wallen (2006), mortality is the changes in sample size as a result of dropout participants. Purposeful sampling helped to deal with learners who were more willing to undertake the study.

Data collector characteristics like age and gender affect the results of the research study. To avoid such a threat, we collected data ourselves from all the learners as advised by Fraenkel and Walle (2006).

When learners' responses were not clear, we interviewed them and member checking was used as a system of external validation (Lewis \& Ritchie, 2003).

\section{External validity}

According to Le Compte and Goetz (1982), there are three factors to be considered as threats to the external validity: history effects, setting effects and construct effects. The strategies and procedures which we employed to avoid these threats are discussed below.

To deal with history effects, Serow (2002) argues that the background of the participants must be known and acknowledged. In this study, it has been noted that learners were purposefully selected from a cohort of 56 eighth-grade learners based on the diagnostic test results.

To deal with Setting effects, Serow's (2002) strategy was adopted by ensuring that all the learners in the study were enrolled in a South African high school system and were taught the same mathematics content.

Construct effects. This is the degree to which abstract expressions, overviews, or connotations are shared across times, sceneries, and populations (Le Compte \& Goetz, 1982). This threat was dealt with as follows: all the learners were familiar with geometry syllabus set by the Department of Basic Education in South Africa. We piloted the diagnostic and post-intervention tests using learners from the same research site. The University of 
South Africa's ethics committee cleared data collection tool: semi-structured interview, diagnostic test and postintervention tests. Intervention activities were aligned to van Hiele's (1999) geometric thinking levels activities as suggested by Crowley (1987).

\section{Reliability}

According to Bloor and Wood (2006) reliability is the degree to which research findings remain the same when the collected data are analysed several times by different researchers. In order to address the issue of reliability with the study the following steps as suggested by Shenton (2004) have been considered in this article:

(i) The research design and its implementation, describing what was planned and executed on a strategic level; (ii) the operational detail of data gathering, addressing the minutiae of what was done in the field; (iii) reflective appraisal of the project, evaluating the effectiveness of the process of inquiry undertaken (p.71).

We have reported in details the findings from the semi-structured interviews and also presented the learners' work that they worked on during the time when the data was collected.

Mechanical recording equipment were utilised in voice recording and video recording during interviews to help during the coding and for future use by any researcher who might require the information in detail.

All the processes of data analysis were well documented (Lacey \& Luff, 2007; Wiersma, 1991) so that other researchers can follow the process in the form of an audit trail at any time.

\section{Intervention}

In every intervention activity, each learner was provided with an A4 paper. For instance, on the paper, triangle $\mathrm{ABC}$ was drawn - along with the A4 paper were the two copies of triangles ABC provided. Figure 1 below illustrate the learning that took place when learners were engaged on hands on learning using the polygon pieces.

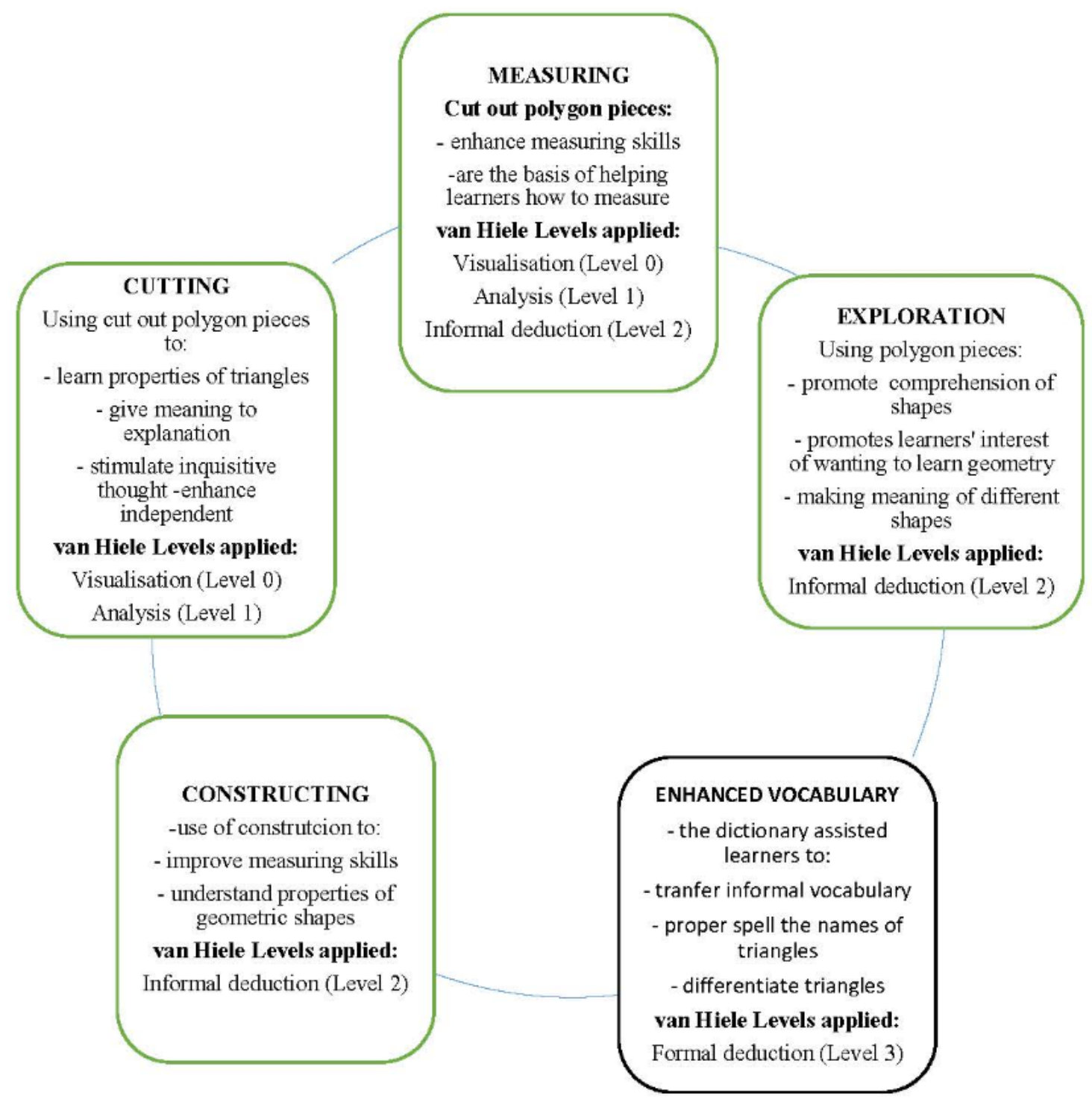

Figure 1. How the polygon pieces and dictionary assisted learners to learn geometry 
Figure 1 shows how the process of cutting out line segments and angles from the given triangle was done. The comparison was done by placing each of the cut out line segments or angles one at a time on top of the other line segment or angle in the original triangle and for every measure taken the results were recorded down. The findings of how the line segments and angles were related in the given triangle were used to describe the properties of that particular triangle. In this activity no rulers and protractors were used, only cut out line segments and angles were used. Even in describing how line segments were related, the informal mathematical language was used, i.e. longer than, shorter than or equal to. For angles, learners would use greater than, smaller than and equal to. When the properties were identified and described the name of that particular triangle was to be written down, the mathematics dictionary was made available to help in enhancing mathematics vocabulary and terminology. The dictionary was used whenever learners felt a need to define and comprehend geometric concepts which were of higher order level.

In each of the planned intervention activities, learners were supposed to answer each and every question after measuring and comparing angles and sides of the given triangles using polygon pieces. Each intervention activity was scheduled for one hour. The total time spent to complete the nine intervention activities was nine hours. The use of polygon pieces assisted by mathematics dictionary was applied in all the intervention activities. As shown in Figure 1 activities were done by cutting out the line segments and angles from the copies provided in order to explore the properties of specific provided triangles. The cut pieces were for the conceptual development of learners in geometry (Hwang \& $\mathrm{Hu}, 2006)$.

Intervention activity 1 consisted of eight questions. All eight questions were aligned to different levels of geometric thinking as follows: question 1.1 was aligned to level 0 - visualisation, questions $1.2 ; 1.4$ and 1.5 were aligned to level 3-formal deduction, questions 1.3 and 1.6 were aligned to level 2-abstraction, and question 1.7(i) (ii) were aligned to level 1-analysis.

Intervention activity 2 had only two main questions that required learners to classify triangles based on their properties and to match the given properties of triangles with the relevant triangles. Both questions were at level 1-analysis of van Hiele theory of geometric thinking.

Intervention activity 3 required learners to identify triangles by name and apply the use of symbols. This intervention had three main questions of which question 3.1 was related to levels 0 -visualisation and 1-analysis of the van Hiele theory geometry thinking, while questions 3.2 and 3.3 were aligned to level 1-analysis of van Hiele theory.

Intervention activity 4 had one question with subsections 4.1 to 4.6 which required learners to match given triangles with the list of properties given. The activity was at level 1-analysis of the van Hiele theory of geometric thinking.

Intervention activity 5 consisted of two questions 5.1(i) - (iii) and 5.2(i) - (v) which required learners to identify and explore the properties of a right-angled triangle. All questions in this activity were aligned to level 1-analysis, except question 5.2 (vi) which was aligned to level 2-abstraction of geometric thinking.

Intervention activity 6 requires learners to explore the properties of obtuse-angled triangles. There are only two questions which are divided into sections. The contents of both questions 6.1(iii) and 6.2(i) - (iii) were at level 1analysis of the van Hiele levels of geometric thinking while 6.2(iv) - (vi) were at level 2-abstraction of the van Hiele levels of geometric thinking. According to the structure of the intervention activity 6(i) and 6.1(ii) were instructions which learner were supposed to follow in order to do question 6.1(iii).

Intervention activity 7 consisted of questions 7.1 and 7.2 in which learners were asked to explore the relationship of angles and line segments by using the physical manipulatives. In this intervention activity questions 7.1(iii) and 7.2 (i) - (iii) were aligned to level 1analysis of the van Hiele levels of geometric thinking while question 7.2(iv) - (vi) was at level 2-abstraction of the van Hiele levels of geometric thinking.

Intervention activity 8 contained questions 8.1 to 8.4 which required learners to explore and discover the properties of an equilateral triangle. Questions 8.1(i) (iii); were aligned to level 0 -visualsation of the van Hiele levels of geometric thinking while question 8.1(iv) and 8.2(i) - (iii) were aligned at level 1 of the van Hiele levels of geometric thinking. Question 8.3(i) - (ii) was at level 3-formal deduction of the van Hiele theory while question 8.4 was at level 2-abstraction of the van Hiele theory.

Intervention activity 9 consisted of questions 9.1 to 9.4 which focused on investigating properties of an isosceles triangle using polygon pieces. In this activity, questions 9.1(i) - (iii) were at level 0-visualisation of the van Hiele theory. Questions 9.1(iv), 9.2(i) - (iii) were at level 1 of the van Hiele levels of geometric thinking. Question 9.3(i) - (ii) were at level 3-deduction while question 9.4 was at level 2-abstraction of the van Hiele levels of geometric thinking.

\section{Ethical Considerations}

According to Stake (2000) and Terrell, (2011) for the research to be deemed good and ethically strict, it should likely not to cause injury to a person engaged in it, hence, to conduct this study ethically, the steps explained below were followed.

Since this study involved eighth-grade learners, consent letters were written to the school governing body through the school principal, Queenstown 
Department of Education and parents of the participants asking for the consent to do the research at the selected school. The research was conducted after school hours.

Purposive sampling was done to select nine learners based on their performance in the diagnostic test (low, middle and high achievers). Learners' names were replaced with codes for anonymity; this was communicated to their parents/guardians in writing.

To avoid the abuse of power by researcher over the participants during the research, both participants and parents were informed that the members of the sample had the freedom to withdraw from the project at any stage. Due to the fact that learners were the participants in this research study, they filled in a consent form with the conditions mentioned in this paragraph.

In order to ensure that the diagnostic and postintervention tests were ethically free, ethical clearance was obtained from the University of South Africa (UNISA). In addition, I have made it a point that the writing of my research report is free of bias towards any of these aspects: age, ethnicity, sexual orientation, race, gender, etc. Lastly, the report covers every aspect in detail so as to give interested readers the opportunity to critic its originality and ethical quality if they want to.

\section{FINDINGS}

Arose from the data analysis of the transcribed semistructured interviews and the reviewed learners' documents the following themes emerged:

\section{Polygon Pieces Enhanced Conceptualisation}

\section{Cutting}

Five of the eight learners said that the cutting of angles and line segments in given triangles to compare dimensions supported their learning of basic geometric concepts. L3 assert that cutting out polygon pieces and comparing triangles' angle and line segments' dimensions made it possible for them to learn properties of triangles. L4 states that using cut out pieces made her/him able to identify the types of triangles. L6 suggested that the use of cut angles and line segments should precede the measuring angles of shapes using the protractor in order to stimulate inquisitive thought and give meaningful explanations. L7 mentions that the cut out pieces made it possible to discover equal angles in triangles. L9 liked the use of cut polygon pieces for the reason that independent learning was enhanced without being told how an isosceles triangle looks like. Learners' responses imply that using cut out polygon pieces of a triangles to learn properties of triangles benefited them a lot in such a way as: (i) instilled meaning to explanation, for example what an equilateral triangle? (ii) stimulated inquisitive thought that enhanced independent learning without being told the properties of triangles by the teacher or a friend.

\section{Constructing}

Five of the eight learners mentioned that construction task they were engaged in helped them learn geometric shapes and their properties. L1 stated that construction and measuring skills improved their understating of geometric terms. L3 suggested that the use of polygon pieces could also be used to explore the association between two bisected angles. L4, L5 \& L8 said that polygon pieces can also be used for the construction of a number of geometric shapes. Two L6 \& L7 said that polygon pieces can be used to measure angles and in algebra, respectively, while L9 said that there is no other way polygon pieces can be used.

From five learners' responses, it is evident that construction of shapes supported by the use of polygon pieces improve measuring skills and conceptual understand properties of geometric shapes.

\section{Measuring}

Triangles' cut out pieces allowed learners to measure sides and angles. Under this theme learner said their different views on how polygon pieces helped them in the learning as follows: L2 said that measuring skills improved their understating of geometric terms. L1 responded that the use of polygon pieces to determine the relationship between angles and sides in a given triangle during the intervention programme enhanced measuring skills. L4 said that polygon pieces assisted with the understanding of the properties of different triangles. L5 asserts that important mathematical skills and knowledge were acquired for the reason that the programme focused on how to measure and not on what it means to measure. L6 \& L8 suggested that the use of cut out angles and line segments should precede the measuring angles of shapes using the protractor in order to stimulate inquisitive thought and give meaningful explanations. The other two (L3 \& L9) didn't comment on this issue, the possibility is that it was due lack of good command of English since it was used as a language of communication.

In a nutshell learners' comments show that they are in support of the use of polygon pieces before they are experience the use of commercial instruments of measuring. Learners captured in this section felt that polygon pieces can be used to lay and enhance measuring skills which are the basis of helping them when learning how to measure.

\section{Polygon pieces' exploration encourages geometric inquiry}

Learners preferred the use of polygon pieces as they enhanced their geometric knowledge. L1 preferred to be taught geometry and other mathematics topics using polygon pieces in order to enhance conceptual understanding. L2 proposed that the best way to help learners comprehend the relationship of angles and sides 


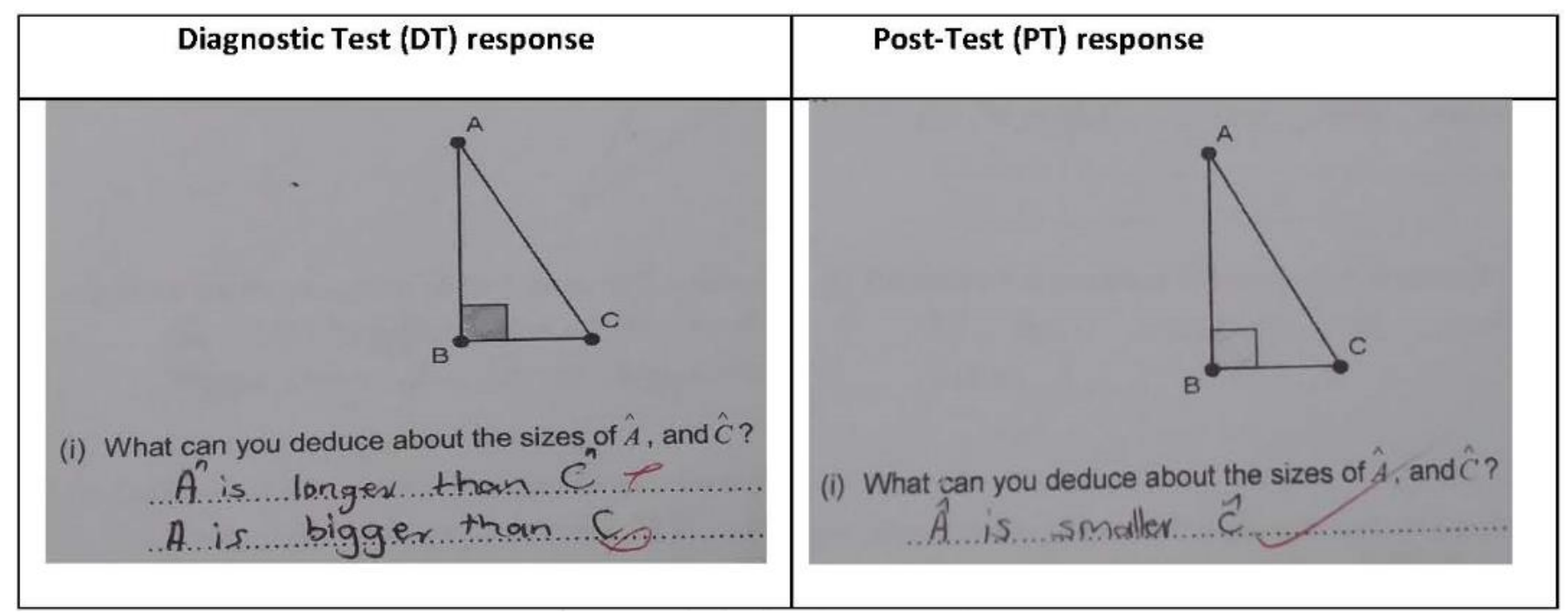

Figure 2. L5's response to question 1.1(i) in both DT and PT

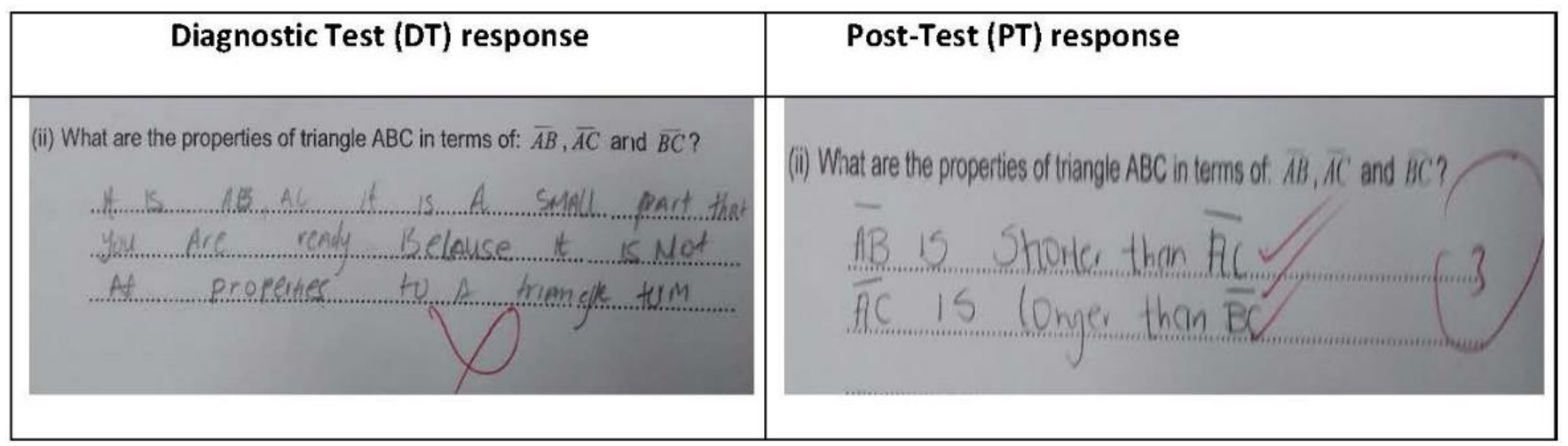

Figure 3. L3's response to question 1.1(ii) in both DT and PT

in a triangle is to engage them in the activities that integrate polygon pieces. L3 recommended that the teaching and learning of mathematics, for example, geometry using polygon pieces was interesting and was of meaning. L4 said that the use of polygon pieces into learning of geometry helped with conceptual understanding of the properties of different triangles. L5 said that polygon pieces have helped them with the identification of triangles while L7 appreciated how the polygon pieces helped them to understand the symbols on triangle, for example on Isosceles triangles. L6, L8 \& L9 had different views which were captured under the first three themes.

Responses by the six learners reveal that the use of polygon pieces in the teaching and learning geometry help learners to comprehend geometric shapes, enhance learners' interest of wanting to learn geometry and help learners to make meaning of different shapes.

\section{Dictionary Enhanced Vocabulary}

\section{Transferring informal vocabulary aided by dictionary}

Figures 2 to 7 show selected sampled learners' responses to certain questions in the Diagnostic Test as compared their responses in the Post-Test after the implementation of mathematics dictionary. The PT results show that most learners improved in geometric vocabulary and terminology, the details of their areas of improvement are presented under each figure.

As shown in Figure 2, in the DT, L5 couldn't respond to question 1.1(i) correctly, after the use of mathematics dictionary in the intervention activities this learner conceptually understood how to use the comparative form 'smaller' when comparing two angles, even though the word 'smaller' was not accompanied by 'than'. The use of the word 'smaller' presented in the PT shows that L5's understanding of geometry migrated to Level 0 visualisation where angles of a figure's magnitudes were compared without using any measuring instrument. In the DT the same learner was uncertain of what response to give that's why there are two responses given.

In the DT, L3 had no idea of what was asked that's why there is something written which has no mathematical meaning at all. After using the dictionary during the intervention activities, in question 1.1(i) of PT, L3 managed to use correct comparative forms, i.e. 'longer than' and 'shorter than', to compare the dimensions of pairs of line segments of the given triangle. L3's vocabulary and terminology were 


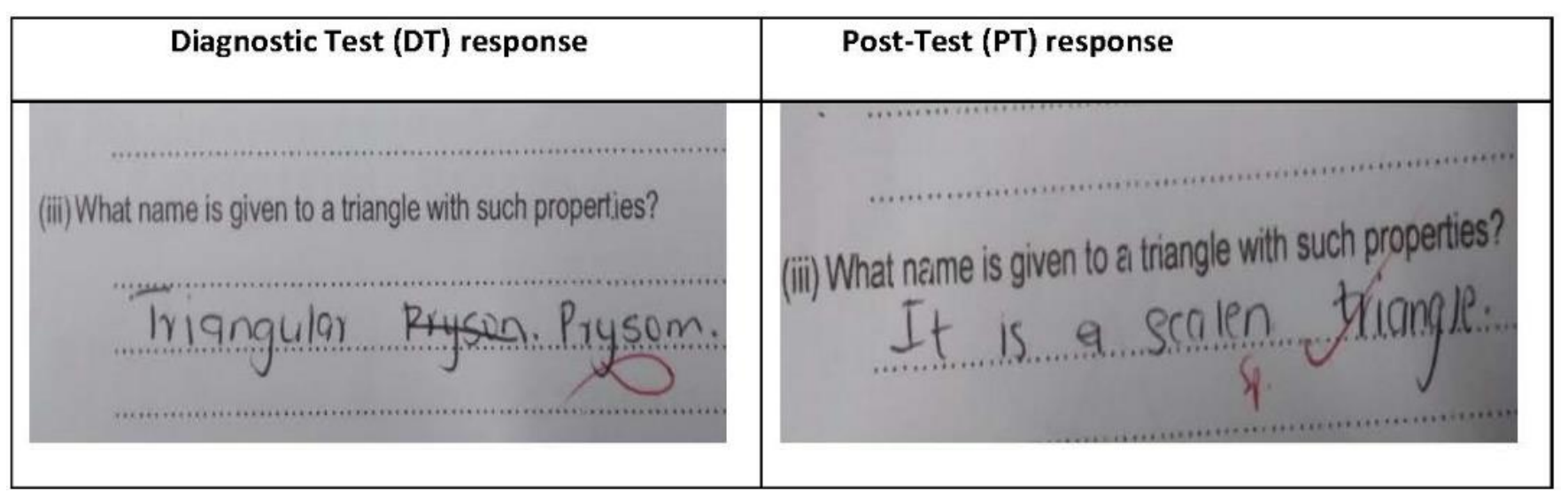

Figure 4. L4's response to question 1.2(iii) in both DT and PT

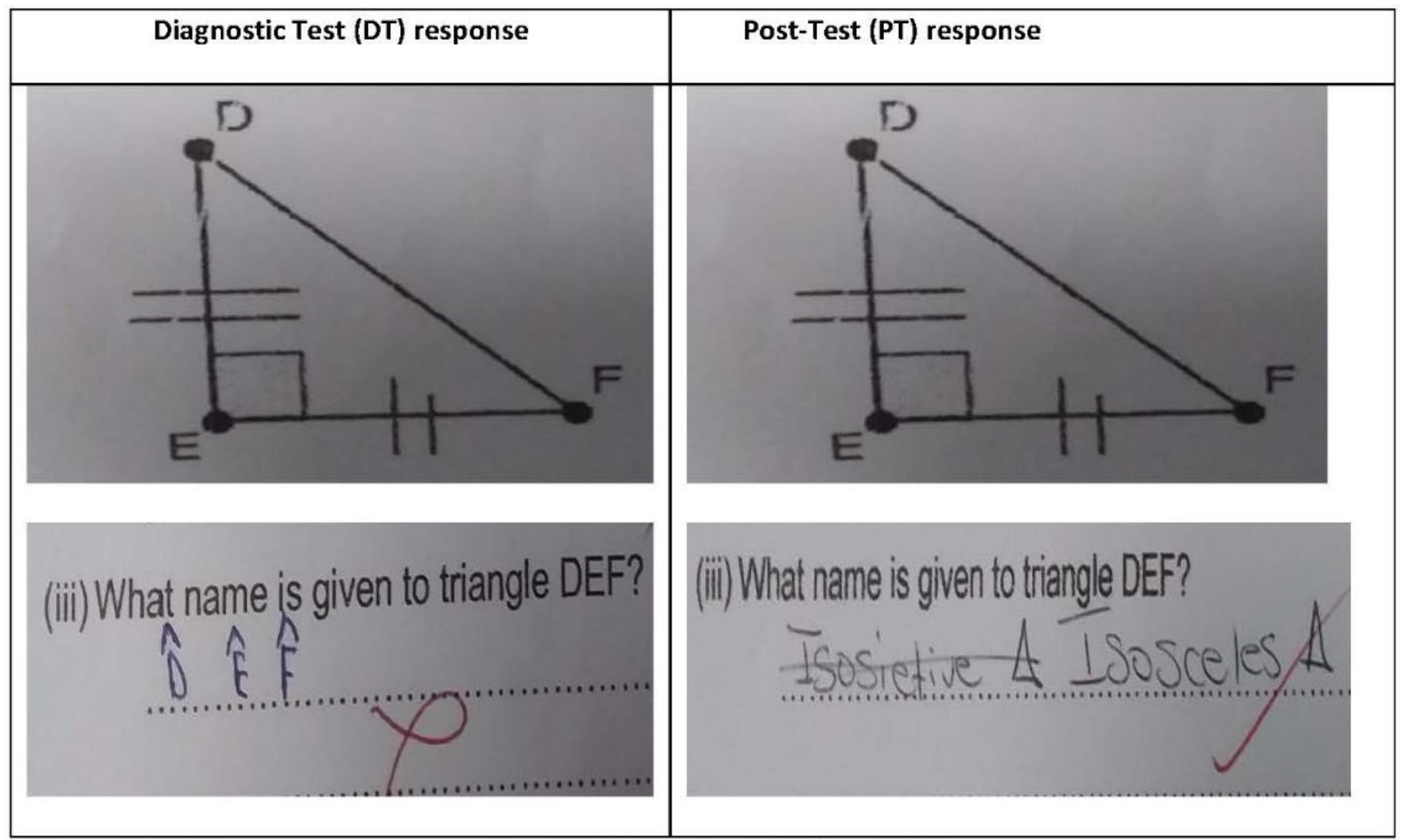

Figure 5. L9's response to question 1.3(iii) in both DT and PT

addressed. by being able to identify minimum sets of properties that describe the given figure. L3 migrated from the level of thinking beyond Level-0 visualisation to Level 2-abstraction of van Hiele's theory which stresses the use of proper terminology. Figure 4 shows how L4 responded to Question 1.1(iii).

L4's response to question 1.2(iii) in the DT as compared to the response of the same question in PT was incorrect, the DT response shows that this learner was struggling with geometric terminology, but that was addressed after the use of mathematics dictionary during the intervention tasks. Dictionary integration helped L4 to move to Level 2-abstraction of van Hiele's geometric theory. L4 demonstrated the improvement in PT by naming a scalene triangle after taking into consideration the angle sizes and line segments' attributes.

The response given in PT shows that after the use of mathematics dictionary during intervention tasks L9 conceptually understood that a shape with features as shown in triangle DEF is known as an isosceles. L9's understanding of question 1.3(iii) in the PT proves that this learner migrated from van Hiele's level of geometric thinking that is beyond Level 0 to Level 0-visualisation. This was demonstrated by L9's ability to name the figure based on the symbols attached to it.

The use of mathematics dictionary in the intervention tasks helped L6 to respond correctly to question 1.4(i) in the PT, but it was a different case in the same question in DT. This conceptual understanding illustrates that L6 


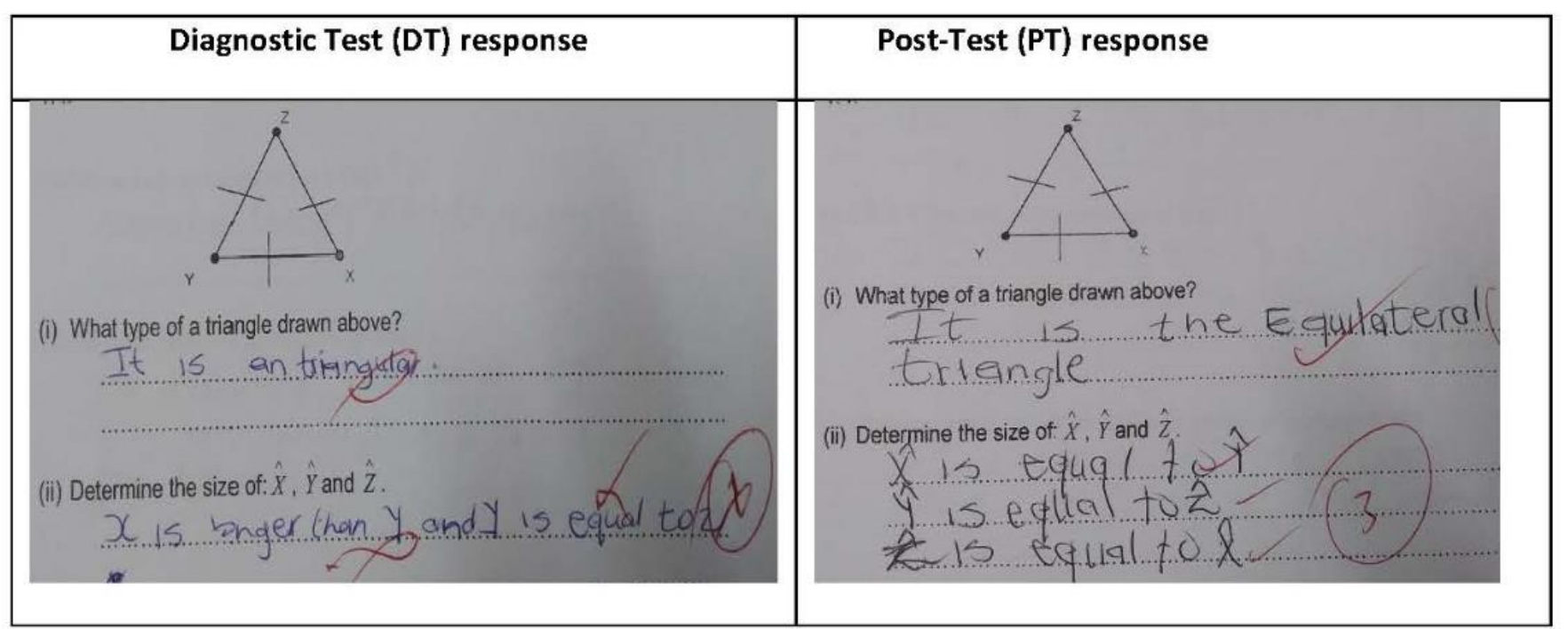

Figure 6. L6's response to question 1.4(i) \& 1.4(ii) in both DT and PT

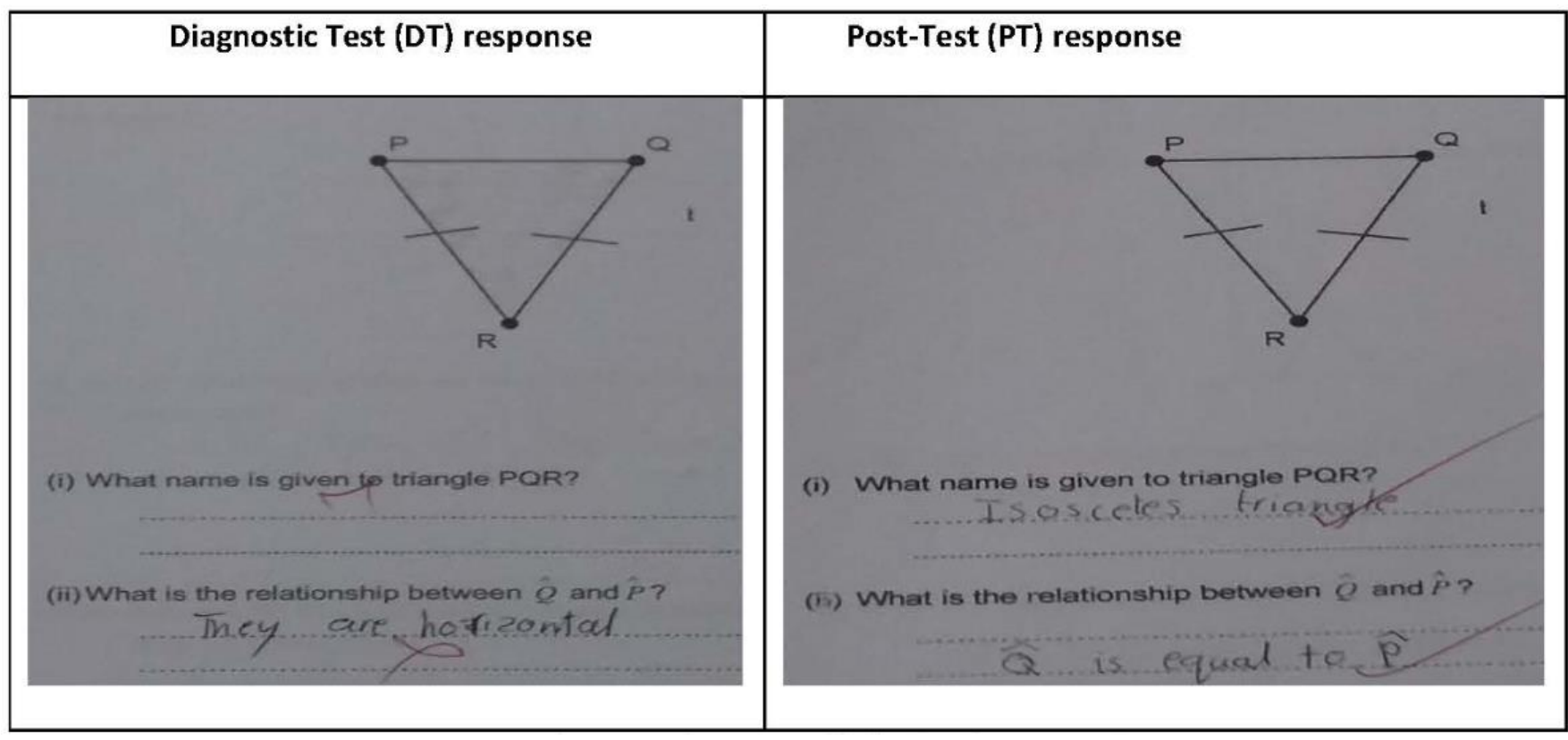

Figure 7. L1's response to question 1.5(i) \& 1.5(ii) in both DT and PT

moved to Level-0 visualisation of van Hiele's geometric theory. In question 1.4(ii) of the DT L6's responses were incorrect, but after the use of mathematics dictionary during the intervention tasks, L6 got it correct in the PT. This shows how L6's geometric thinking migrated to Levels 2 and 3 of van Hiele's theory by being able to look for inclusion to described the figure and to identify what to be proved in a figure. Figure 7 reflects on L1's responses to question 1.5(i) and 1.5(ii).

In DT question 1.5(i) L1 couldn't give any response. Leaving a space with no answer means that L1 had no idea to the question. After the use of the dictionary during the intervention L1 managed to respond correctly to the same question in the PT, it shows that L1's geometric thinking migrated from beyond visualisation to Level 0-visualisation of van Hiele's theory. Level 0visualisation in question 1.5(i) learners were to use of the correct terminology to describe the given figure. Question 1.5(ii) was at Level 2-abstraction at this level L1 was supposed to describe the relationship of the two angles in a triangle considering the given symbols. In DT, L1 couldn't respond correctly, but after being engaged in an intervention that made use of the dictionary and polygon pieces, the response to question 1.5(ii) in PT was correct.

\section{DISCUSSION OF FINDINGS}

The results findings are discussed in this section. The discussion is based on learners' response during the semi-structured interviews and the reviewed learners' work. The evidence from learners' responses revealed that the integration of polygon pieces and mathematics dictionary into the learning of geometry had a positive impact to their learning of the properties of triangles. A 
number of benefits were highlighted by most learners, which were: (i) the use of polygon pieces allowed learners to gain measuring skills. Most learners used the measuring skills to learn the properties of different triangles. (ii) polygon pieces allowed most of the learners to be engaged in a geometric inquiry, for example, investigation of the properties of an equilateral triangle. These comments concur with Alex and Mammen's (2018) findings which state that the adoption of various visual and concrete representations promote mathematical terminology and mathematical language.

The results of how learners benefitted from the use of mathematics dictionary are presented in Figures 2 to 7 . Data presented in Figures 2 to 7 indicate different challenges learners had in the concepts of geometry like spellings, sentence constructions, the definition of triangles and properties of triangles. Responses in the DT reveal that most of the learners struggle with the geometric terminology and vocabulary and these influence their performance badly. The study has revealed that learners not only struggle with the proving of geometric theorems only but also geometric terminology and vocabulary become barriers to the learning of geometric concepts. This finding is in agreement with the earlier results of Riccomini, et al. (2015) who found out that there are many challenges for learners in their learning of the language of mathematics, most of them struggle to comprehend most of the essential mathematical concepts.

\section{CONCLUSION}

From the results the following conclusions were made:

i. The integration of mathematics dictionary into the teaching and learning is imperative since it helps learners to geometric terminology and vocabulary.

ii. The use of polygon pieces when teaching geometry has a positive impact, they make intangible concepts tangible which leads to conceptual understanding.

iii. Mathematics dictionary and polygon pieces should complement and supplement each other to enhance learners' mathematical understanding.

\section{ACKNOWLEDGEMENTS}

My sincere gratitude should go to the following for helping me to make it during the main research study:

My research site principal, $\mathrm{HoD}$ for mathematics, staff, school governing board and the parents for granting me permission to conduct the research at their school.

The research participants (learners) who sacrificed and committed their time to attend to my programme after school for two weeks.
UNISA for granting me with an opportunity to study and for the bursary that I received to support my studies.

\section{REFERENCES}

Alex, J. K. (2012). The evaluation of an instructional framework using the van Hiele levels for learning and teaching geometry: A case study in five rural senior secondary schools. Unpublished doctoral dissertation, Walter Sisulu University, Mthatha, South Africa.

Alex, J. K., \& Mammen, K. J. (2014). An assessment of the readiness of Grade 10 learners for geometry in the Context of Curriculum and Assessment Policy Statement (CAPS) Expectation. International Journal of Education Science, 7(1), 29-39. https:/ / doi.org/10.1080/09751122.2014.11890167

Alex, J. K., \& Mammen, K. J. (2016). Lessons learnt from employing van Hiele theory based instruction in senior school geometry classroom. Eurasia Journal of Mathematics, Science E Technology Education, 12(8), 2223-2236. https:/ / doi.org/10.12973/eurasia.2016. $1228 \mathrm{a}$

Blanco, L. J. (2001). Errors in the Teaching/Learning of the Basic Concepts of Geometry. International Journal for Mathematics Teaching and Learning, pp. 111. Retrieved from http://www.cimt.org.uk/ journal/lberrgeo.pdf

Bloor, M., \& Wood, F. (2006). Keywords in Qualitative Methods: A Vocabulary of Research Concepts. London: Sage. https://doi.org/10.4135/9781849209403

Bowen, G. A. (2009). Document Analysis as a Qualitative Research Method. Qualitative Research Journal, 9(2), 27-40. https:/ / doi.org/10.3316/QRJ0902027

Bussi, M. G. B., \& Frank, A. B. (2015). Geometry in early years: sowing seeds for a mathematical definition of squares and rectangles. ZDM Mathematics Education, 47(3), 391-405. https:/ / doi.org/10.1007/ s11858-014-0636-5

Clements, D. H., \& Battista, M. T. (1992). Geometry and spatial reasoning. In D. A. Gouws (Ed.), Handbook of research on mathematics teaching and learning (pp. 420-464). New York, NY: MacMillan.

Clements, D. H., \& Sarama, J. (2011). Early childhood teacher education: The case of geometry. Journal of Mathematics Teacher Education, 14(2), 133-148. https:/ / doi.org/10.1007/s10857-011-9173-0

Corbin, J., \& Strauss, A. (2008). Basics of qualitative research: Techniques and procedures for developing grounded theory (3rd ed.). Thousand Oaks, CA: Sage. https:/ / doi.org/10.4135/9781452230153

Correa, C. A., Perry, M., Sims, L. M., Miller, K. F., \& Fang, G. (2008). Connected and culturally embedded beliefs: Chinese and US teachers talk about how their learners best learn mathematics. Teaching and 
Teacher Education, 24, 140-153. https://doi.org/ 10.1016/j.tate.2006.11.004

Fraenkel, J. R., \& Wallen, N. E. (2006). How to Design and Evaluate Research in Education (6 ${ }^{\text {th }}$ ed.). New York, NY: McGraw-Hill.

Fujita, T., \& Keith, J. (2003). The place of experimental tasks in geometry teaching: learning from the textbooks design of the early 20th Century. Research in Mathematics Education, 5(1), 47-62. https:/ / doi.org/10.1080/14794800008520114

Glaser, B. G., \& Strauss, A. L. (1967). The discovery of grounded theory: Strategies for qualitative research. Chicago: Aldine. https://doi.org/10.1097/ 00006199-196807000-00014

Hwang, W. Y., \& Hu, S. S. (2013). Analysis of peer learning behaviours using multiple representations in virtual reality and their impacts on geometry problem solving. Computers $\mathcal{E}$ Education, 62(0), 308319. https://doi.org/10.1016/j.compedu.2012.10. 005

Lacey, A., \& Luff, D. (2007). Qualitative data analysis. The NIHR RDS for the East Midlands / Yorkshire \& the Humber.

Laski, E. V., Jor'dan, J. R., Daoust, C., \& Murray, A. K. (2015). What makes mathematics manipulatives effective? Lessons from Cognitive Science and Montessori Education, 1-8. https:/ / doi.org/10.1177/ 2158244015589588

LeCompte, M., \& Goetz, J. P. (1982). Problems of reliability and validity in ethnographic research, Review of Educational Research, 52(1), 31-60. https:/ / doi.org/10.3102/00346543052001031

Lewis, J., \& Ritchie, J. (2003). Generalising from qualitative research. In J. Ritchie \& J. Lewis (Eds.), Qualitative Research Practice: A Guide for Social Science Learners and Researchers (pp. 263-286). London: Sage.

Luria, A. R. (1976). Cognitive development: Its cultural and social foundations. Cambridge, MA: Harvard University Press.

Marshall, M. N. (1996). Sampling for qualitative research. Family Practice, 13, 522-525. https://doi.org/10.1093/fampra/13.6.522

Morin, J. E., \& Franks, D, J. (2009) Why Do Some Children Have Difficulty Learning Mathematics? Looking at Language for Answers. Preventing School Failure: Alternative Education for Children and
Youth, 54(2), 111-118. https://doi.org/10.1080/ 10459880903217861

Moss, J. Hawes Z, Naqvi S., \& Caswell, B. (2015). Adapting Japanese Lesson Study to enhance the teaching and learning of geometry and spatial reasoning in early years classrooms: a case study. ZDM Mathematics Education, 47, 377-390. https:/ / doi.org/10.1007/s11858-015-0679-2

Puchner, L., Taylor, A., O’Donnell, B., \& Fick, K. (2008). Teacher learning and mathematics manipulatives: A collective case study about teacher use of manipulatives in elementary and middle school mathematics lessons. School Science and Mathematics, 108, 313-325. https://doi.org/ 10.1111/j.1949-8594.2008.tb17844.x

Reddy, V., Visser, M., Winnaar, L., Arends, F., Juan, A., Prinsloo, C. H., \& Isdale, K. (2016). TIMSS 2015: Highlights of Mathematics and Science Achievement of Grade 9 South African Learners. Human Sciences Research Council.

Riccomini, P. J., Smith, G. W., Hughes, E. M., \& Fries K. M. (2015). The Language of Mathematics: The Importance of Teaching and Learning Mathematical Vocabulary. Reading $\mathcal{E}$ Writing Quarterly, 31(3), 235-252. https://doi.org/10.1080/ 10573569.2015.1030995

Shenton, A. K. (2004). Strategies for ensuring trustworthiness in qualitative research projects. Education for Information 22, 63-75. https:/ / doi.org/10.3233/EFI-2004-22201

Steele, M. D. (2013). Exploring the mathematical knowledge for teaching geometry and measurement through the design and use of rich assessment tasks. Journal of Mathematics Teacher Education, 16, 245-268. https://doi.org/10.1007/ s10857-012-9230-3

Van den Heuvel-Panhuizen, M., Elia, I., \& Robitzsch, A. (2015). Kindergartners' performance in two types of imaginary perspective-taking. ZDM Mathematics Education, 47, 345-362. https://doi.org/10.1007/ s11858-015-0677-4

Van Hiele, P. M. (1999). Developing geometric thinking through activities that begin with play. Teaching children mathematics, 5(6), 310-317.

Van Teijlingen, E. R., \& Hundley, V. (2001). The importance of pilot studies. In N. Gilbert (Ed.) Social Research update, University of Surrey.

Wiersma, W. (1991). Research Methods in Education: An Introduction, Boston: Allyn and Bacon.

\section{http://www.ejmste.com}

